\title{
Carcinogenetic mechanisms of endocrine disruptors in female cancers (Review)
}

\author{
LINO DEL PUP ${ }^{1}$, ALBERTO MANTOVANI $^{2}$, CARLA CAVALIERE $^{3}$, GAETANO FACCHINI $^{3}$, AMALIA LUCE $^{4}$, \\ PASQUALE SPERLONGANO ${ }^{5}$, MICHELE CARAGLIA $^{4}$ and MASSIMILIANO BERRETTA ${ }^{6}$ \\ ${ }^{1}$ Division of Gynecological Oncology, CRO Aviano, National Cancer Institute, I-33081 Aviano; ${ }^{2}$ National Institute of Health, \\ I-00161 Rome; ${ }^{3}$ Division of Medical Oncology, Department of Uro-Gynaecological Oncology, Istituto Nazionale Tumori \\ 'Fondazione G. Pascale' - IRCCS, I-80131 Naples; ${ }^{4}$ Department of Biochemistry, Biophysics and General Pathology, \\ Second University of Naples, I-80138 Naples; ${ }^{5}$ Unit of General and Geriatric Surgery, School of Medicine, \\ Second University of Naples, I-80137 Naples; ${ }^{6}$ Department of Medical Oncology, CRO Aviano, \\ National Cancer Institute, I-33081 Aviano, Italy
}

Received January 5, 2016; Accepted January 30, 2016

DOI: 10.3892/or.2016.4886

\begin{abstract}
Endocrine disruptors (EDs) are pollutants that alter the endocrine system and are involved in carcinogenesis. EDs have multiple and complex levels of action. They can affect the synthesis, release and transport of natural hormones. In target tissues, EDs can reduce or increase the effects of natural hormones on their receptors and change signaling cascades. When ED exposure happens at critical periods of life, from embryo to puberty, they can act at doses considered safe for an adult. Furthermore, their epigenetic effects can also influence the cancer risk of future generations. The cancer mechanisms of known EDs are hereby reviewed, There are thousands of newly introduced substances whose potential endocrinedisrupting and cancer effects are completely unknown. Although there are still gaps in our knowledge, these data support the urgent need for health and environmental policies aimed at protecting the public and in particular, the developing fetus and women of reproductive age.
\end{abstract}

\section{Contents}

1. Introduction

2. Literature search methods

Correspondence to: Dr Michele Caraglia, Department of Biochemistry, Biophysics and General Pathology, Second University of Naples, Via L. De Crecchio 7, I-80138 Naples, Italy

E-mail: michele.caraglia@alice.it

Dr Lino Del Pup, Division of Gynecological Oncology, CRO Aviano, National Cancer Institute, Via Gallini 2, I-33081 Aviano, Italy E-mail:1delpup@cro.it

Key words: female cancer, endocrine disruptor, pesticide, dioxin, phthalate, bisphenol a, heavy metal, phytoestrogen carcinogenesis
3. Endocrine disruptors and their effects on the development of female tumors

4. Conclusion

\section{Introduction}

Endocrine disruptors (EDs) are exogenous chemicals that can interfere with any aspect of hormone action; therefore, they can disrupt normal mammary and female genitalia development, function and carcinogenesis, especially when exposure occurs during early life (1).

The mechanisms by which EDs can also modify the risk of hormone-sensitive female neoplasms, such as breast or endometrial cancers, are multiple, interacting and complex. They can act at very low doses, with non-linear dose response curves (2). They can affect the synthesis of natural hormones, their release and/or transport. In target tissues, EDs can reduce or increase the effects of natural hormones on their receptors and/or they can change signaling cascades. Hormone metabolism and changes in elimination can be the final part of their indirect endocrine interference.

Carcinogens induce cancer or promote tumor growth by mechanisms such as increased expression of oncogenes, decreased expression of tumor suppressors, changes in expression of cell cycle or apoptosis regulator genes (3). With the exception of diethylstilboestrol (DES), EDs cannot be considered carcinogens per se, but they can indirectly interfere with the endocrine and immune systems favoring true carcinogenic effects (4).

Breast cancer is the most common cancer in women. Mammary gland growth and function are influenced by multiple endocrine-mediated mechanisms/pathways that may be altered by thousands of EDs, mostly when they act during vulnerable periods, such as embryogenesis or during breast maturation, from puberty to the first full term pregnancy (5).

Currently available epidemiologic human data are inadequate to support a conclusion concerning the association of 
EDs and endometrial, tubal or ovarian cancer, mostly because they are based on adult data, on professional or accidental high dose/short term exposure while there are no data on newly introduced environmental pollutants (6).

\section{Literature search methods}

We performed a review mainly based on Medline search. Other databases were used to retrieve literature including Scopus and Trip Database.

\section{Endocrine disruptors and their effects on the development of female tumors}

The supposed carcinogenic mechanisms of the most known EDs (pesticides, DDT, dioxins, phthalates, bisphenol A, diethylstilbestrol, heavy metals) are here reviewed and summarized in Figs. 1-6.

Dioxins. To date dioxins are the EDs most convincingly associated with breast cancer in exposed humans. Dioxins are a class of environmental chemicals exemplified by 2,3,7,8-tetrachlorodibenzo- $p$-dioxin (TCDD). Dioxins and dioxin-like compounds interact with specific polymorphisms to enhance breast cancer risk (7) (Fig. 1).

Dioxins act through the aryl hydrocarbon receptor (AhR), a ligand-activated nuclear transcription factor, intracellular mediator of xenobiotic signaling pathways. This ligand-dependent transcription factor mediates a range of biological and toxicological effects, all pivoting around the cell responses to endogenous (e.g., endogenous hormones) and exogenous (e.g., xenobiotic) challenges. Due to the common mechanisms and occurrence in the same matrices, the intake and body burden of dioxins are evaluated in a cumulative way, each compound contributing to the toxic equivalent (TEQ) of a given mixture in biological samples, its concentration and potency (expressed as AhR activation); the dioxin TEQ is a rare example of a straightforward use of in vitro cell biology data (AhR activation potency) into risk assessment. Dioxins in females act as anti-estrogenic EDs as AhR activation leads to a reduction in ER transcriptional activity, which is more pronounced on ER $\beta$ than on ER $\alpha$. Interestingly, several studies have found an increased risk of breast cancer associated with high body burdens of dioxin-like PCB in conjunction with certain genetic polymorphisms involved in carcinogen activation and steroid hormone metabolism (7).

A single oral dose of the most potent dioxin compound (TCDD) to pregnant rats at term organogenesis and just prior migration of the mammary bud into the fat pad (gestational day 15) is sufficient to impair differentiation and increase expression levels of ER $\alpha$ of terminal ductal structures in adult rats, although the tissue retained the ability to differentiate in response to estrogen. Mammary epithelial transplantation between control and TCDD-exposed females suggests that the stroma plays a major role in the TCDD-induced retarded development of the mammary gland. In mice exposed in utero, the TCDD effect on breast histogenesis was much more pronounced than the slight effects on hormone levels, suggesting that, rather than affecting steroid balance, dioxins act directly on breast tissue differentiation. Due to the persistence and long half-life of TCDDs, in these studies, the exposure of rodent conceptuses and pups likely continued beyond the initial dosing and throughout lactation. This is supported by in vitro findings on SCp2 mammary epithelial cells, where TCDD reduced the expression of genes involved in cell adhesion and milk secretion (8). Interestingly, downregulation of superoxide dismutase was the main long-term change in protein expression observed in mammary glands from rats exposed in utero; thus, TCDD may render the mammary tissue ill-equipped to deal with subsequent free radical exposure.

The Seveso Women's Health Study was comprised of 981 women, who were infants to 40-years of age in 1976 , resided in the most contaminated areas and had archived data that were collected soon after the infamous chemical accident in 1976. In breast cancer patients, individual TCDD body burden was significantly related with tumor risk (9). The pleiotropic effects of such a potent hormone trigger as TCDD was also associated with an increased morbidity and mortality from lymphohematopoietic and other neoplasms as well as markers of altered endocrine-immune function and they were often gender-related. In the Seveso industrial accident, TCDD exposure appeared to reduce the risk of uterine cancer, but the number of cases was too small for a comprehensive evaluation (10). Finally, one potentially relevant effect was the clear link between exposure levels in men and a lowered male/ female gender ratio in their offspring (11).

$D D T$.DDT is a prototypal representative of persistent, bio-accumulating contaminants of the food chain. Notwithstanding the severe use restrictions since the 1970's and the banning in Europe as a pesticide in 1986, residues are still found in feeds, foods and in the fat deposits of living organisms, including humans. Actually DDT is a mixture of DDT and DDE isomers, all able to bio-accumulate and make up the body burden of DDT and related compounds. The isomers $p, p^{\prime}$-DDT and $o, p^{\prime}$-DDE show estrogenic activity both in vitro and in vivo, whereas other isomers, such as the very persistent $p, p^{\prime}$-DDE (also a metabolite) are mainly antiandrogenic.

Long-term exposure to DDT through food could be hypothesized to increase the risk for developing estrogen-dependent tumors such as breast cancer. However literature is discordant (12). In 1993 Wolff et al (13) observed that the risk of breast cancer was higher among women with high serum concentrations of DDE, the major metabolite of DDT, compared with women with low levels. Since then, a substantial number of epidemiologic studies have investigated this hypothesis. In humans DDT/DDE body burden has been associated with breast cancer (early, peripubertal exposure) and with endometrial cancer [ongoing exposure (14)] (Fig. 1). The antiandrogenic $p, p$-DDE may accelerate tumor onset in mice and there is a trend for positive correlation of breast cancer with DDE, which was not significant, due to low statistical power (15).

A review article by Calle et al (16) and a meta-analysis (17) of the epidemiologic evidence for tissue DDE concentrations and breast cancer, have not found an association between breast cancer risk and ED body burden in different scenarios. However, an important caveat to these studies remains largely unexplored: the importance that age at exposure may have in breast cancer development. Indeed there is a paucity of evidence regarding exposure at critical time periods (17). Some studies (18-20) have observed positive associations between 


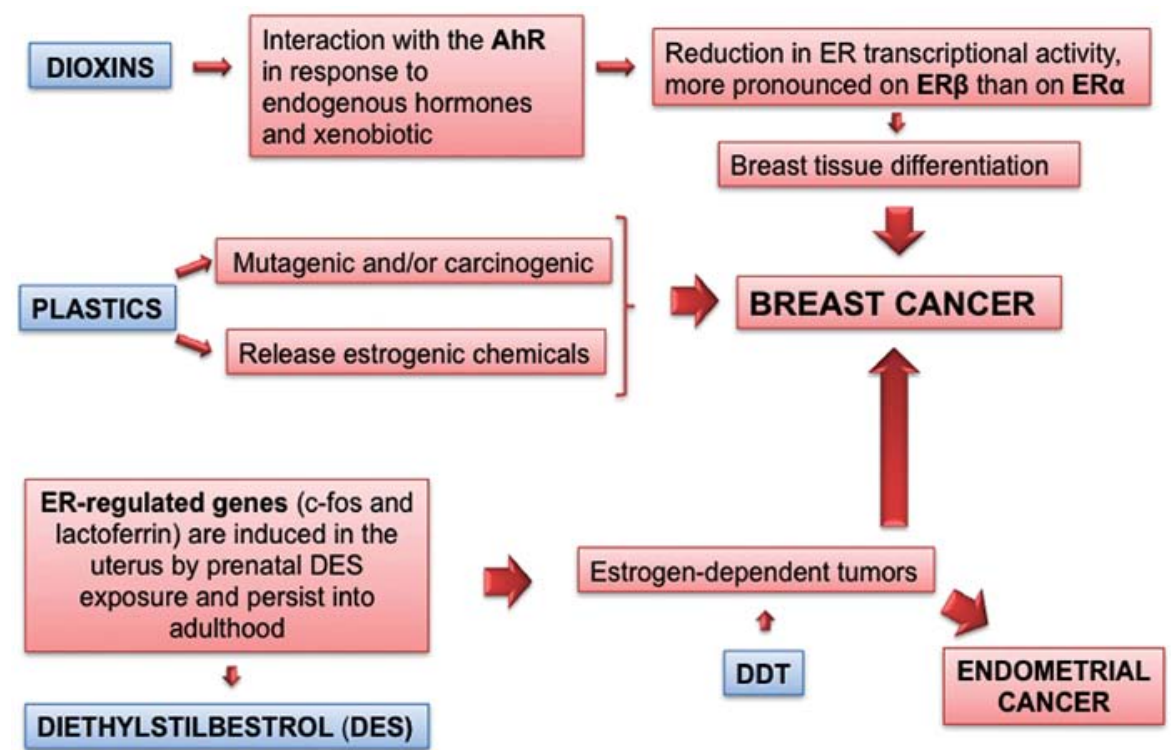

Figure 1. Schematic diagram of the action of dioxins, plastics, DDT and diethylstilbestrol (DES) on the modulation of breast and endometrial cell proliferation.

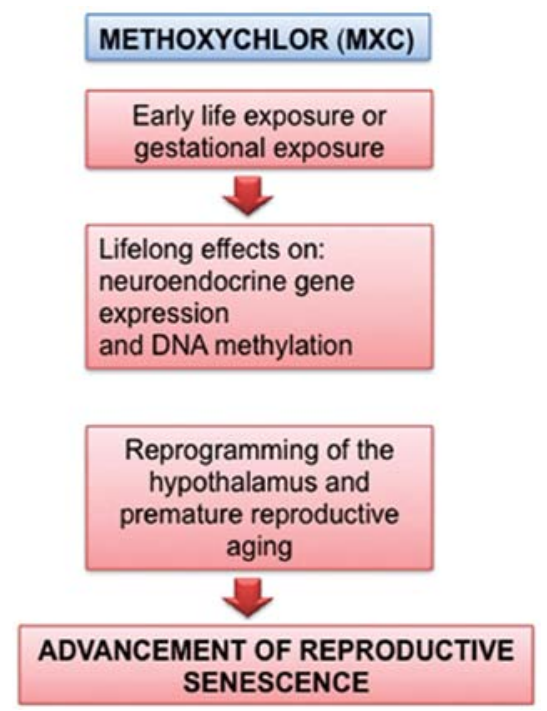

Figure 2. Schematic diagram of the action of methoxychlor (MXC) on the advancement of reproductive senescence.

insecticides and breast cancer. The reasons for these discrepancies are difficult to identify, but it may be plausible that these studies provide a different focus on the role of contributing factors impinging on breast cancer risk together, and in synergy, with organochlorines. A finding worth mentioning has been observed in the US Agricultural Health Study: breast cancer risk was elevated among women whose husbands had used dieldrin $(\mathrm{RR}=2.0)$, a chlorinated insecticide closely related to DDT, but not when used by the women themselves. There was no clear association of breast cancer risk with farm size or washing of clothes worn during pesticide application, but the risk was modestly elevated among women whose homes were closest to areas of pesticide application (21).

However, conclusions are somewhat different when examining the risk related to the body burden resulting from the dietary exposure in the general population.
Evidence from a prospective study of young women in California who had their blood samples drawn in 1959-1967 found a significantly increased risk of breast cancer with increasing levels of serum $p, p^{\prime}$-DDT. Women in the highest exposure category had a 5-fold significant increase in risk (22). This was a nested case-control study among a cohort of female members of the Kaiser Permanente Health Plan in Oakland, CA and used stored blood samples collected to assay for serum $p, p^{\prime}$-DDT. The unique circumstances surrounding the study have permitted the investigation of early-life exposure to DDT and future breast cancer risk during a time when DDT was actively being used in the United States. A recent meta-analysis has not confirmed that current exposure levels to DDT/DDE increases the risk of breast cancer in humans (23).

Methoxychlor. Methoxychlor (MXC) was introduced as a less persistent alternative to DDT but, unfortunately, many studies have demonstrated that $\mathrm{MXC}$ is also an estrogenic ED (24). Gestational exposure to MXC disrupts the female reproductive system with lifelong effects on neuroendocrine gene expression and DNA methylation, as well as faster reproductive senescence. Animal and recent epidemiological studies showed that reproductive aging was accelerated by ED developmental exposures: besides MXC, also bisphenol A, dioxins and perfluorocarbons were highlighted (Fig. 2). By hastening senescence and/or increasing cancer risk, EDs may eliminate the possibility of biological children for women who may postpone childbirth for personal or professional reasons. Considering the important roles of estrogens on targets in the body and brain, early reproductive senescence may also accelerate various disease-related states associated with menopause, and affect the quality of life in the aging population of women (25).

Atrazine and triazine herbicides. Atrazine is the prototypal representative of this group of herbicides. These compounds act as EDs in female rats by altering the secretion of luteinizing hormone $(\mathrm{LH})$ and prolactin at the hypothalamic-pituitary 

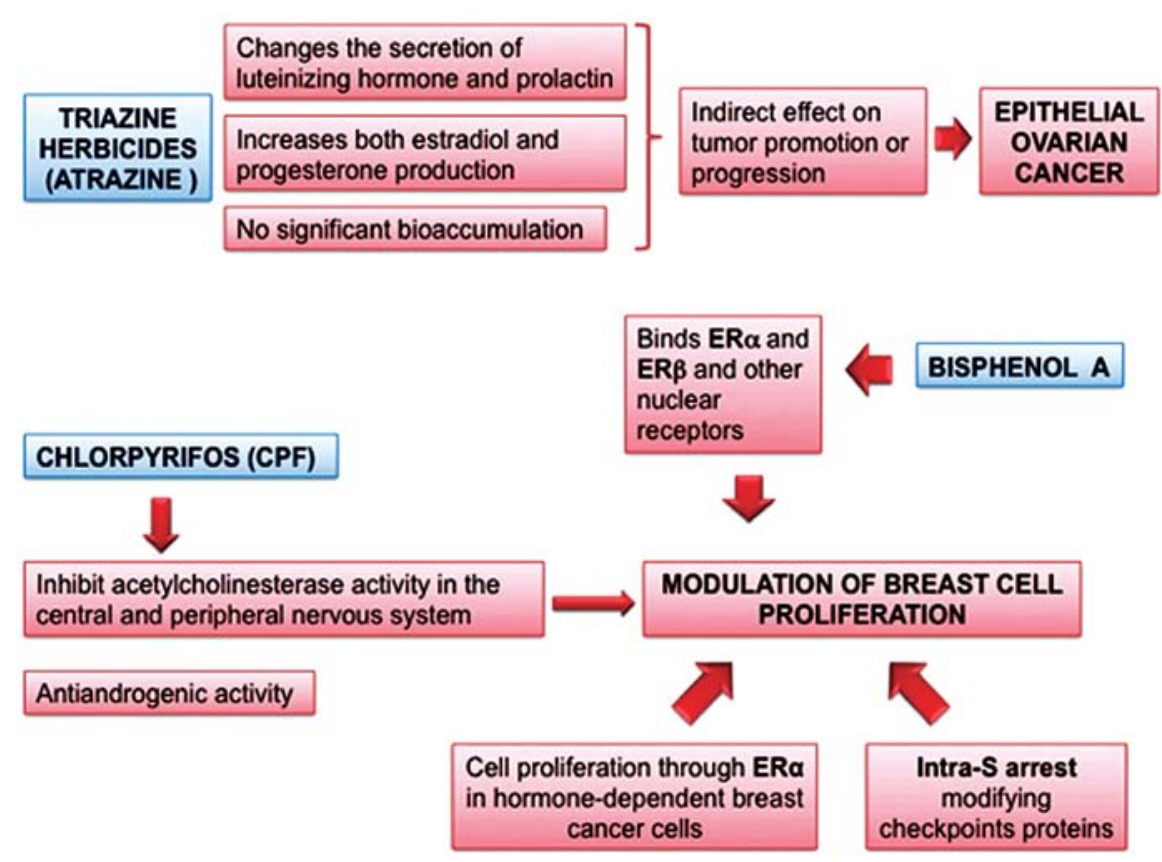

Figure 3. Schematic diagram of the action of triazine herbicides (atrazine), bisphenol A and chlorpyrifoson in the modulation of breast cell proliferation.

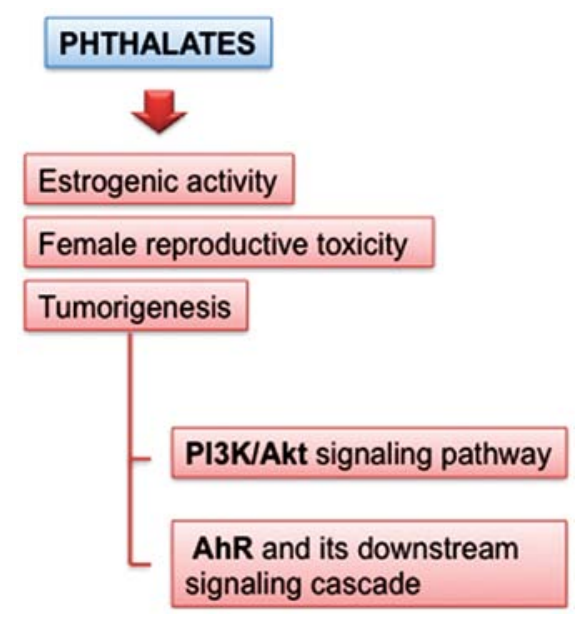

Figure 4. Schematic diagram of the action of phthalates on tumorigenesis pathways.

level. Triazine herbicides have no significant bioaccumulation potential, but they can be significant pollutants of water bodies (Fig. 3). Atrazine is an example of species and strainspecific induction of mammary tumors. Adult female Sprague-Dawley rats fed with diet-supplemented atrazine developed mammary tumors earlier and with increased incidence, when compared to controls, while this findings was not observed in other rats (26). In Sprague-Dawley rats, atrazine caused a persistent estrus with a prolonged and sustained estrogen secretion from ovarian follicles, which failed to ovulate due to the herbicidal action on gonadotropin balance. This mechanism of ovulation failure is fundamentally different from menopause in women.

Previous studies have demonstrated an increased risk of ovarian cancer among women exposed to triazine herbicides. Notably, triazine herbicides are among the very few EDs for which an epidemiological association with epithelial ovarian cancer might be hypothesized (27).

Chlorpyrifos and other pesticides. The 2,4,5-trichlorophenoxypropionic acid and the fungicide captan were found to significantly increase the risk of post-menopausal breast cancer among women whose husbands used such pesticides ( $R R=2.0$ and 2.7, respectively). The risk was moderately higher when the residence was close to the pesticide application area. Some indications, not statistically significant, of an increased risk for breast cancer were found in premenopausal women using specific organophosphorus insecticides, in particular chlorpyrifos, dichlorvos, and terbufos (Fig. 3) (28). A significantly increased risk of breast cancer was also associated with self-reported residential pesticide use; however, due to the study design, no dose response trend was observed and it was, indeed, difficult to detect (29).

The Agricultural Health Study also found increased ovarian cancer risk among women employed as private pesticide applicators ( $\mathrm{SIR}=2.97)(30)$.

Low and environmentally relevant concentrations of glyphosate possess estrogenic activity and alter both ER $\alpha$ and ER $\beta$ expression. Glyphosate-based herbicides are widely used for soybean cultivation, and our results also found that there is an additive estrogenic effect between glyphosate and genistein, a phytoestrogen in soybeans (31).

Summing up the overall data, there is no conclusive evidence on non-occupational insecticide exposure and breast cancer. These compounds can modulate several mechanisms of carcinogenesis, in particular in the breast, but the cell type-specific responses are at nanomolar range concentrations. While some cancer cell lines, such as MCF-7, exhibit a significant increase in all the cancer mechanisms, other cell lines, such as MDA-MB-231, exhibit a markedly reduced invasion potential following exposure to pesticides (32). Thus it is difficult to predict the overall net cancer effect, without 


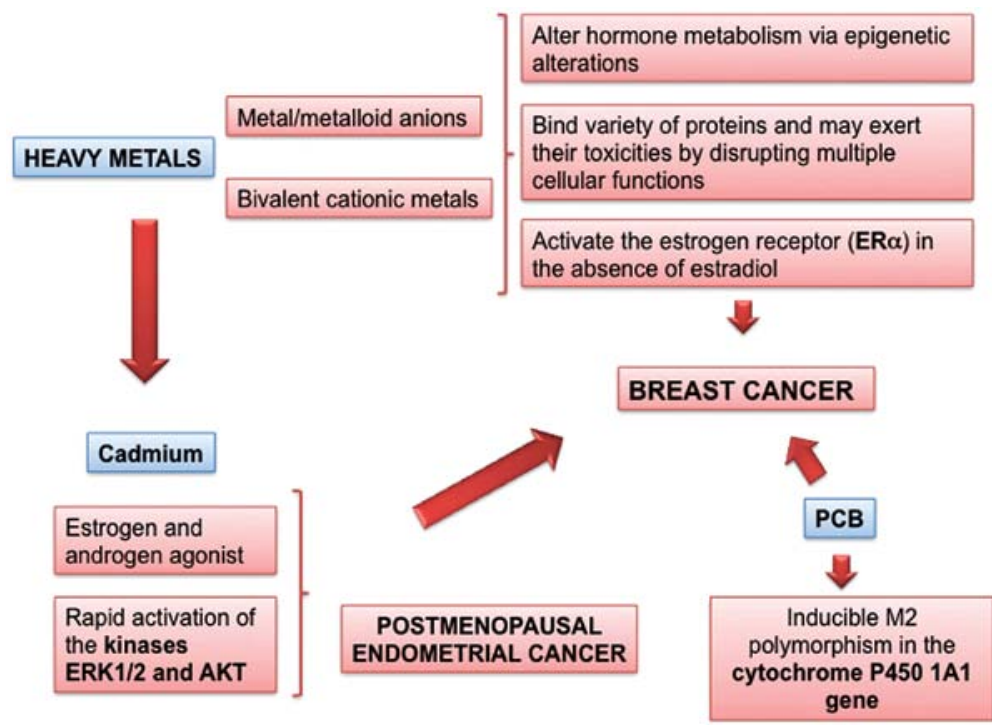

Figure 5. Schematic diagram of the action of heavy metals and polychlorinated biphenyls (PCBs) on the development of breast and postmenopausal endometrial cancer.

specifying the ED, dose, exposure time and the particular type of cancer cell.

Phthalates. Phthalates are a large family of synthetic high-production chemicals used in polyvinyl chloride (PVC) plastics, beauty and infant products, medical devices, as well as in enteric coating of some medications. In the general population, exposure accounts for approximately $2 \mathrm{mg} / \mathrm{day}$, while occupational and medical exposures can reach much higher levels. Phtalates are believed to act on steroid biosynthesis, affecting also the early steps in liver.

Several groups have documented the ability of phthalates to cause female reproductive toxicity and the subject has been previously reviewed (Fig. 4) (33). Phtalates such as butyl phthalate (BBP), di- $n$-butyl phthalate (DBP) and di-2-ethylhexyl phthalate (DEHP) are not only capable of inducing a proliferative effect through the PI3K/AKT signaling pathway but also of displaying estrogenic activity even at a very low concentration (34).

Notwithstanding the widespread diffusion and the relevant effects and mechanisms, no studies have been performed on the possible association between phthalate exposure and female cancer risk. Nevertheless a growing body of evidence suggests that EDs contribute to female reproductive disorders, mostly phthalates. Phthalate attributable endometriosis cases across the European Union have been estimated at 56,700 and 145,000 women, respectively, with total combined economic and health care costs potentially reaching $€ 163$ million and $€ 1.25$ billion (35). These public health costs should be considered as the EU contemplates regulatory action on EDs. When compared with population-based controls, the risk of endometrioid clear cell ovarian cancer for women with endometriosis is 3-times greater (36). As the life-time risk of ovarian cancer is significantly increased in endometriosis patients from approximately 1 to $2 \%$ (37) and phthalates can contribute to endometriosis with a probability of causation of $20-39 \%$, further studies on phthalates and ovarian cancer are warranted. Breast cancer and endometriosis share some common environmental and molecular risk factors; thus this is a further area of research (38).

Bisphenol A. Bisphenol A [BPA, 2,2,-bis(hydroxyphenyl) propane] is one of the highest-volume chemicals produced worldwide. BPA is a plasticizer found in reusable plastic containers, food and beverage can liners, baby bottles and dental sealants, among others. Originally synthesized as an estrogenic compound, it is currently utilized to manufacture food and beverage containers resulting in uptake with food and drinks. According to an opinion issued by EFSA in 2015 (39), adolescents are the population group with the highest aggregate (oral plus dermal) exposure to BPA $(1.449 \mu \mathrm{g} / \mathrm{kg} \mathrm{BW})$, taking into account that the substance has been forbidden in baby bottles in Europe since 2011 .

Humans are widely exposed to BPA through plastic goods, food and drink packaging, and thermal paper receipts. BPA is the best-studied ED and it is the only one for which effects of exposure have been described at multiple time points spanning fetal development and postnatal life. Bisphenol A is such a widespread industrial chemical, that, albeit a non-persistent chemical, it is consistently found in body fluids, due to continuous environmental exposure. Internal levels appear to be higher in infertile compared to fertile women (40). There is concern that exposure to low doses of BPA, defined as less than or equal to $5 \mathrm{mg} / \mathrm{kg}$ body weight/day, may have developmental effects on various hormone-responsive organs as it is detected in body fluids of more than $90 \%$ of the human population.

BPA exposure has become an important health concern based on its ability to 'leach' from these products and enter the materials contained within them. Elevated temperature and extreme $\mathrm{pH}$ further increase the leaching of BPA from food containers. Human exposure has been confirmed in various tissues including ovarian follicular fluid, and various exposures have been linked to reproductive effects in animal models (41).

In the long-term, BPA exposure was found to result in an increase in the number of epithelial structures and in the 


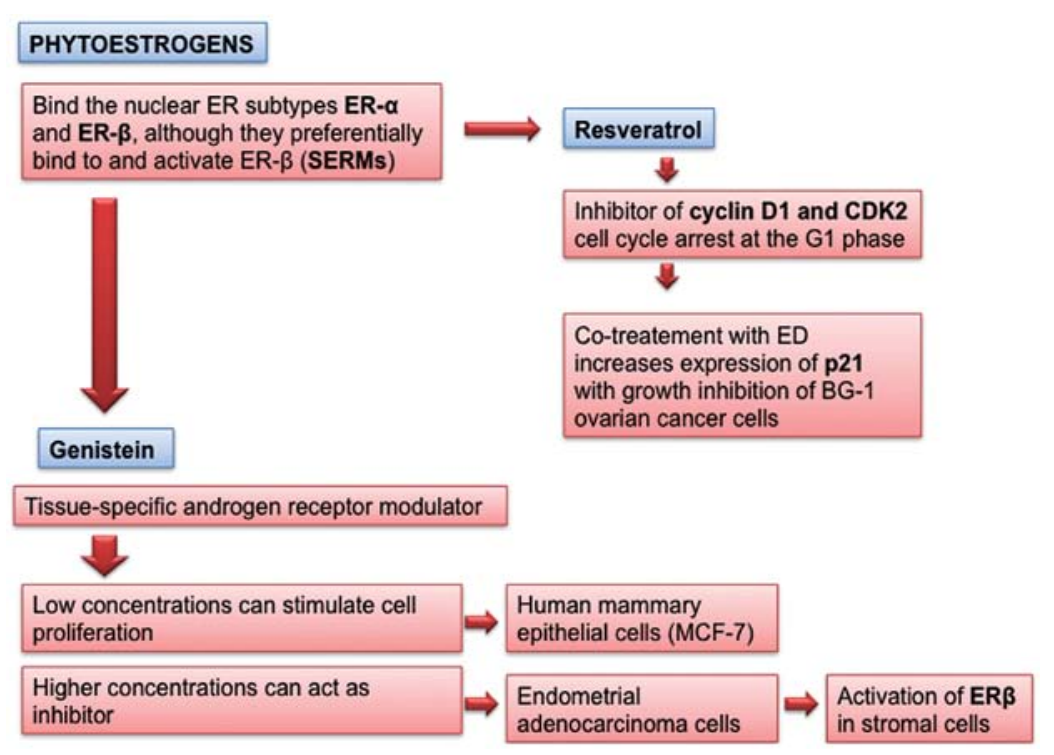

Figure 6. Schematic diagram of the action of phytoestrogens and polychlorinated biphenyls (PCBs) on the development of breast and postmenopausal endometrial cancer.

development of pre-cancerous and cancerous lesions in the mammary glands of rodents that are manifested in adulthood. The effects of BPA on mammary development and tumorigenesis in rodents are used as a paradigmatic example of how altered prenatal mammary development may lead to breast cancer in humans (Fig. 3). Changes in the stroma and its extracellular matrix led to altered ductal morphogenesis. Additionally, gestational and lactational exposure to BPA increased the sensitivity of rats and mice to mammotropic hormones during puberty and beyond, thus suggesting a plausible explanation for the increased incidence of breast cancer (41).

Perinatal exposure to environmentally relevant doses of BPA alters long-term hormone response that may increase the propensity to develop breast cancer (42). BPA may also alter epigenetic regulation of relevant gene panels, possibly supporting breast cancer promotion.

BPA is considered an 'estrogenic' $\mathrm{ED}$, binding to both $\mathrm{ER} \alpha$ and ER $\beta$, but it may interact with other nuclear receptors as well, e.g., antagonism with androgen receptor and agonism with pregnane $\mathrm{X}$ receptor. As for other EDs, experimental studies on BPA essentially addressed the possible link with breast cancer, rather than with ovarian or endometrial cancer.

BPA-induced tissue changes in the mammary gland were found to include enhanced estradiol sensitivity, increased presence of progesterone receptor-positive ductal cells and enhanced ductal terminal end branching in the epithelium, while the stroma associated with hyperplastic ducts had more fibrous tissue and mast cells (43). Ductal hyperplasias and carcinoma in situ with increased number of estrogen receptor- $\alpha$ positive cells were present in adult rats (44). This gland phenotype was not be unique to rats as it was observed also in mice exposed from organogenesis through to lactation (45). The mode of action could involve a stromal effect: BPA accelerates the maturation of the adipose tissue pad of the mammary gland and alters collagen localization, thereby possibly altering the fat-epithelium interactions. Oral BPA exposure of rat dams during lactation increased the suscep- tibility to a later challenge with DMBA as evidenced by the increased numbers of tumors per rat and the shortened latency period (46); BPA exposure caused increased cell proliferation and progesterone receptor expression and decreased apoptosis. Since BPA (contrary to, e.g., DDT or PCB) is still a widely used chemical, there is (understandably) a lively debate about the relevance of these findings to risk assessment. The BPA effects on mammary programming are observed at dose levels (down to $0.25 \mathrm{mg} / \mathrm{kg} \mathrm{BW}$ ) far below the NOAEL ( $5 \mathrm{mg}$ / $\mathrm{kg}$ BW) derived from standard toxicological studies; contrary to fat-soluble chemicals, the bioaccumulation potential and excretion in milk are low for BPA, thus there are uncertainties about the actual neonatal and peripubertal exposure. Most important, several experiments used injection, thus using a route not relevant for the general population and by-passing liver-mediated conjugation, an important detoxification step in BPA metabolism. On the other hand, the effects observed are consistent across experiments and across species (rats and mice); the internal exposure achieved may be relevant to actual human exposures (47).

Continuous and/or repeated exposure to BPA may also play a role in tumor progression and poorer patient outcome (49). For instance, BPA exposure in vitro elicited a pattern of gene expression related with higher tumor aggressiveness in epithelial-stromal co-cultures from breast cancer patients (48).

Diethylstilboestrol. Diethylstilboestrol (DES) is a potent estrogen agonist. It is the most well-known example of an ED eliciting transplacental carcinogenesis. Young adult offsprings exposed in utero to this potent drug had a higher rate of reproductive tract abnormalities in both genders as well as a higher rate of the rare clear-cell vaginal adenocarcinoma in female ones (50). Neonatal treatment of mice on post-natal days 1-5 with DES has been shown to cause uterine adenocarcinoma by 18 months, similar to the use of the phytoestrogen genistein (51).

The timing of exposure is critical to the potential development of uterine cancer. In fact, treatment of adult mice with comparable levels of DES did not induce uterine neoplasms. 
Direct evidence of a link between prenatal estrogen exposure and breast cancer risk has been gathered from a cohort of women born to mothers treated with the potent synthetic estrogen DES during pregnancy (Fig. 1). Breast cancer risk at 40 years of age and older was 2.5 -fold higher in the DES-exposed women.

This potent estrogenic agent, known for its transplacental carcinogenesis when used as a drug in the 1960's, has been used as an experimental model to explore the developmental anomalies that increase the susceptibility to mammary gland neoplasia later in life, due to the proliferative estrogen-like effects.

DES has been investigated also as an experimental model for endometrial cancer. Since the endometrium in primates is shed and regenerates monthly, the key target cells for initiating endometrial cancer are most likely a lineage of non-shedding cells, possibly of a stem cell-type. This scenario is in accordance with the hypothesized tumorigenic action of ED by altering the developmental programming of target tissues. ER-regulated genes, such as c-fos and lactoferrin, are induced in the uterus by prenatal DES exposure and persist into adulthood (Fig. 1). Also neonatal exposure of mice to DES was found to lead to ER $\alpha$-dependent tumorigenesis in the uterus. The Eker rat strain is specifically vulnerable to another uterine alteration induced by neonatal DES, leiomyomas (52). Leiomyomas developed in rats exposed in utero, displayed an enhanced proliferative response to steroid hormones compared to tumors in unexposed animals. The induction of leiomyomas was highly dependent on the developmental window. In adult myometrium, the expression of the estrogen-responsive gene calbindin $\mathrm{D}(9) \mathrm{K}$ and the progesterone receptor were reprogrammed in females exposed to DES at days 3 to 5 (preimplantation) and days 10 to 12 (organogenesis) but not in those exposed at days 17 to 19 (late fetal period). Reprogramming in response to DES exposure resulted in a hyper-responsiveness to ovarian hormones. Since the resistant period coincided with the time at which reproductive tract tissues were exposed to endogenous estrogen, the data suggested that the programming was most vulnerable to estrogenic ED when the uterine tissue was in an estrogen-naïve state (52). The experimental studies performed with such a potent endocrine-active agent as DES, often performed by parenteral administration, have been difficult to extrapolate to environmental EDs, also because these are usually far less potent. However, the DES studies provided a detailed insight on the mechanisms by how early ED exposure may predispose reproductive tissues to cancer.

Cadmium and heavy metals. Cadmium has been classified as a human carcinogen by the International Agency for Research on Cancer (IARC, Lyon, France) (53). Cadmium is widely dispersed into the environment through industrial emission, waste incineration, and combustion of fossil fuels. Even in industrially non-polluted areas, farmland may become contaminated by atmospheric deposition and by the use of cadmium-containing fertilizers and sewage sludge. The highest concentration of cadmium in food can be found in shellfish, offal products, and certain seeds; however, because of a comparatively high accumulation of cadmium in agricultural crops and a high consumption of these products, the main sources of dietary cadmium exposure $(80 \%)$ are bread and other cereals, potatoes, root crops, and vegetables. Cadmium may induce cancer by several mechanisms, such as aberrant gene expression, inhibition of DNA damage repair, induction of oxidative stress and inhibition of apoptosis. Cadmium has features of an ED, as it is an estrogen, and even an androgen mimetic that may promote the development of estrogen-dependent malignancies, such as breast and endometrial cancer (Fig. 5). Both in vitro and in vivo studies have provided evidence that cadmium may act as a metalloestrogen. The estrogen-mimicking effects of cadmium on mammary gland are associated with the interaction to nuclear ER $\alpha$ and its hormone-binding domain, as well as with the activation of membrane-bound estrogen receptors.

Cadmium exposure is positively associated with the risk of breast cancer and increased mammographic density. Cadmium is a slow-acting, pro-oxidant toxic metal which is also an ED; it acts as an estrogen and androgen agonist in vivo and in vitro and can cause rapid activation of the kinases ERK1/2 and AKT in human breast cancer-derived cells, like estradiol (54). There are epidemiological indications linking the exposure to cadmium with breast cancer (55) and postmenopausal endometrial cancer (56). Oily seeds like flaxseed are a dietary source of cadmium: interestingly, rat offspring exposed in utero and during lactation to a diet high (up to 10\%) in flaxseed were more susceptible (shorter latency, more tumors per rat) to the rat mammary carcinogen 7,12-dimethylbenz(a)anthracene (DMBA). Flaxseed exposure did not alter the mammary gland differentiation, but altered the ER expression in gland structures, namely, it increased ER $\alpha$ and especially reduced ER $\beta$. Although the link between the effects and cadmium exposure was inferential, the observed changes were strongly suggestive of an effect by an estrogen-active ED; since flaxseed is naturally rich in lignans, which are considered as phytoestrogens, a contribution by the high intake of these compounds may not be ruled out.

The role for dietary cadmium in postmenopausal breast cancer development was confirmed by a prospective study cohort of 55,987 postmenopausal women (57). During an average of 12.2 years of follow-up, 2,112 incident cases of invasive breast cancer were ascertained (1,626 ER ${ }^{+}$and $\left.290 \mathrm{ER}^{-}\right)$. After adjusting for confounders, including consumption of whole grains and vegetables (which accounted for $40 \%$ of the dietary exposure, but also contained putative anticarcinogenic phytochemicals), dietary cadmium intake was positively associated with overall breast cancer tumors [rate ratio (RR), 1.21; $95 \%$ confidence interval $\left.(\mathrm{CI}), 1.07-1.36 ; \mathrm{P}_{\text {trend }}=0.02\right]$. Among lean and normal weight women, statistically significant associations were observed for all tumors (RR, 1.27; 95\% CI, 1.07-1.50) and for $\mathrm{ER}^{+}$tumors (RR, 1.25; 95\% CI, 1.03-1.52) and similar, but no statistically significant associations were found for $\mathrm{ER}^{-}$tumors (RR, 1.22; 95\% CI, 0.76-1.93).

In a large population-based prospective cohort of women, the Swedish Mammography Cohort (56) found a statistically significant positive association between dietary cadmium exposure and risk of endometrial cancer. During 16.0 years (484,274 person-years) of follow-up there were 378 incident cases of endometrioid adenocarcinoma. The average estimated dietary cadmium intake was $15 \mu \mathrm{g}$ /day (80\% from cereals and vegetables). Cadmium intake was statistically significantly associated with increased risk of endometrial 
cancer in all women; the multivariate relative risk was 1.39 [95\% CI, 1.04-1.86; $\mathrm{P}_{\text {trend }}=0.019$ ], comparing highest fertile versus lowest. Among never-smoking women with body mass index (BMI) of $<27 \mathrm{~kg} / \mathrm{m}^{2}$, the relative risk was $1.86(95 \%$ CI, 1.13-3.08; $\left.\mathrm{P}_{\text {trend }}=0.009\right)$. We observed a 2.9-fold increased risk (95\% CI, 1.05-7.79) associated with long-term cadmium intake consistently above the median at both baseline and in never-smoking women with low bio-available estrogen (BMI of $<27 \mathrm{~kg} / \mathrm{m}^{2}$ and nonusers of postmenopausal hormones).

Heavy metals present in cigarettes may substantially contribute to tumorigenesis by inducing intercellular ROS accumulation, increased expression of oncogenic and anti-apoptotic markers (58).

A recent meta-analysis and systematic review (59) based on population-based studies, concluded that the frequency of breast cancer may be an indicator of the early genetic effects for cadmium-exposed populations. A meta-analysis based on individual data might provide more precise and reliable results. Therefore, it is necessary to construct an international database on genetic damage among populations exposed to cadmium that may contain all raw data of studies examining genetic toxicity

Polychlorinated biphenyls. Polychlorinated biphenyls (PCBs) are a large group of different persistent organic pollutants (POPs) that could induce cytochrome P4501A1 (CYP1A1), which is involved in the metabolism of steroid hormones and polycyclic aromatic hydrocarbons in humans (Fig. 5) (60).

The cytochrome P450 1A1 (CYP1A1) is a member of the CYP1 family. It participates in the metabolism of a vast number of xenobiotics, as well as endogenous substrates, and the $\mathrm{A} 2455 \mathrm{G} \mathrm{G}$ allele is a risk factor for breast cancer among Caucasian subjects (61).

Discrete windows of susceptibility to toxicants have been identified for the breast, including in utero, puberty, pregnancy, and postpartum. PCB measured during the early postpartum predicts an increased risk of maternal breast cancer diagnosed before age 50. In the Child Health and Development Studies cohort (62), PCB 167 was associated with a lower risk [odds ratio $(\mathrm{OR}), 75$ th vs. 25 th percentile $=0.2,95 \% \mathrm{CI}, 0.1-0.8]$ as was PCB 187 (OR, 75th vs. 25th percentile $=0.4,95 \%$ CI, 0.1-1.1). In contrast, PCB 203 was associated with a 6-fold increased risk (OR, 75th vs. 25th percentile $=6.3,95 \% \mathrm{CI}, 1.9-21.7$ ). The net association of PCB exposure, estimated by a post-hoc score, was nearly a 3-fold increase in risk for breast cancer (OR, 75th vs. 25th percentile $=2.8,95 \%$ CI, 1.1-7.1) among women with a higher proportion of PCB 203 in relation to the sum of PCBs 167 and 187. Postpartum PCB exposure as well as pregnancy exposure, may predict increased risk for early breast cancer, depending on the mixture that represents the internal dose. It remains unclear whether individual differences in exposure, response to exposure, or both, explain the risk patterns observed.

Phytoestrogens. Studies on the relationship between soy consumption and risk of breast cancer are discordant: foods rich in phytoestrogens (PEs) may have complex actions exerting both preventive and promoting effects (63). Ingestion before puberty, when the mammary gland is relatively immature seems protective (64). A meta-analysis indicates that high soy intake might reduce the risk of developing premenopausal breast cancer but has no effect on post-menopausal breast cancer risk (65). The effects of ingestion of dietary PEs by breast cancer patients and survivors is also controversial $(66,67)$. High consumption of soy products and other legumes is associated with a decreased risk of endometrial cancer for the highest compared with the lowest quartile of soy intake (68). However, a randomized doubled-bind, placebocontrolled study on 298 post-menopausal women showed an increased incidence of endometrial hyperplasia following 5 years of treatment with $50 \mathrm{mg}$ of soy isoflavones (69). Thus, PE supplements should be reconsidered, particularly in women at high risk for endometrial cancer. Indeed, PE can cause both proliferative and anti-proliferative effects, depending on tumor cell type, concentrations, timing of phytoestrogen exposure and type of PE given. They bind to nuclear ER subtypes ER $\alpha$, but they preferentially bind to and activate ER $\beta$ (Fig. 6).

Genistein, the main soy isoflavone, stimulates the growth of estrogen-sensitive mammary cancer cells in vitro at low concentrations (0.1-10 mM), whereas at higher concentrations $(\geq 10 \mathrm{mM}$ ) it is an inhibitor. It is not only a selective estrogen receptor modulator, but also a tissue-specific androgen receptor modulator as it affects androgen receptor (AR)-mediated gene expression.

The interactions with genistein and ED xenobiotics may be quite complex, ranging from antagonism to additivity depending on thr substances and experimental systems.

Several experimental studies have explored the complex links between PE action and endometrial proliferation. While daidzein potentiates estrogen-induced endometrial cell proliferation (70), genistein inhibits it, possibly through activation of $\mathrm{ER} \beta$ in stromal cells at low concentrations (nM), while much higher $(\mu \mathrm{M})$ concentrations increase endometrial proliferation or uterine leiomyomas, through non-genomic ER signaling, which determines epigenetic changes (71). Overall, the findings suggest some caution towards high intakes of isoflavones through, e.g., supplements or 'healthy' products.

Phytoestrogens could also have other complex, indirect, interfering, or protective mechanisms, in particular, suppression of the activity of the aromatase enzymes, which are responsible for conversion of androgens to estrogens; induction of apoptosis in human breast cancer cells, also in ER-negative cell lines, which supports the occurrence also of hormone-independent mechanisms of action; inhibition of tyrosine kinase activity, involved in a number of growth factor signaling pathways, implicated in the control of cell growth and differentiation; antioxidant activity; stimulation of the immune system and inhibition of angiogenesis.

Resveratrol (trans-3,4,5-trihydroxystilbene; RES), a naturally occurring $\mathrm{PE}$, has a growth inhibitory effect on the cell viability effect of BPA on BG-1 human ovarian cancer cells. It could be a candidate for prevention of tumor progression caused by EDs, including BPA via effective inhibition of the crosstalk of ER $\alpha$ and IGF-1R signaling pathways (Fig. 6) (72).

\section{Conclusion}

Various carcinogenetic mechanisms of main endocrine disruptors have been documented, yet we are still far from the full knowledge of the female cancer effects of the multitude of 
complex interacting pollutants. EDs can dysregulate hormone signaling and cell function through multifaceted molecular, cellular and biochemical mechanisms (73). Chronic exposure to EDs can permanently alter physiological hormone signaling (74) and it may provoke epigenetic and genetic modifications in tissue stem cells that can lead to cancer (75).

The research findings can help us to better understand ED-related cancer mechanisms (76) and to identify possible ways to prevent cancer through fundamental changes in lifestyle that can effectively counter bio-accumulation of certain EDs (77).

Although we do not know the clinical impact of the potential carcinogenetic effects of each ED (76), also invoking the precautionary principle, these findings support the urgent need for health and environmental policies aimed at protecting the public in general, and, in particular, the developing fetus and women of reproductive age.

\section{References}

1. Macon MB and Fenton SE: Endocrine disruptors and the breast: Early life effects and later life disease. J Mammary Gland Biol Neoplasia 18: 43-61, 2013.

2. US Environmental Protection Agency: Endocrine Disruptors Research.

3. Maqbool F, Mostafalou S, Bahadar H and Abdollahi M: Review of endocrine disorders associated with environmental toxicants and possible involved mechanisms. Life Sci 145: 265-273, 2016.

4. Soto AM and Sonnenschein C: Environmental causes of cancer: Endocrine disruptors as carcinogens. Nat Rev Endocrinol 6: 363-370, 2010.

5. Hilakivi-Clarke L, de Assis S and Warri A: Exposures to synthetic estrogens at different times during the life, and their effect on breast cancer risk. J Mammary Gland Biol Neoplasia 18: 25-42, 2013.

6. Caserta D, Maranghi L, Mantovani A, Marci R, Maranghi F and Moscarini M: Impact of endocrine disruptor chemicals in gynaecology. Hum Reprod Update 14: 59-72, 2008.

7. Brody JG, Moysich KB, Humblet O, Attfield KR, Beehler GP and Rudel RA: Environmental pollutants and breast cancer: Epidemiologic studies. Cancer 109 (Suppl 12): 2667-2711, 2007.

8. Collins LL, Lew BJ and Lawrence BP: TCDD exposure disrupts mammary epithelial cell differentiation and function. Reprod Toxicol 28: 11-17, 2009

9. Warner M, Eskenazi B, Mocarelli P, Gerthoux PM, Samuels S, Needham L, Patterson D and Brambilla P: Serum dioxin concentrations and breast cancer risk in the Seveso Women's Health Study. Environ Health Perspect 110: 625-628, 2002.

10. Bertazzi A, Pesatori AC, Consonni D, Tironi A, Landi MT and Zocchetti C: Cancer incidence in a population accidentally exposed to 2,3,7,8-tetrachlorodibenzo-para-dioxin. Epidemiology 4: 398-406, 1993.

11. Pesatori AC, Consonni D, Bachetti S, Zocchetti C, Bonzini M, Baccarelli A and Bertazzi PA: Short- and long-term morbidity and mortality in the population exposed to dioxin after the 'Seveso accident'. Ind Health 41: 127-138, 2003.

12. Laden F, Collman G, Iwamoto K, Alberg AJ, Berkowitz GS, Freudenheim JL, Hankinson SE, Helzlsouer KJ, Holford TR, Huang HY, et al: 1,1-Dichloro-2,2-bis(p-chlorophenyl)ethylene and polychlorinated biphenyls and breast cancer: Combined analysis of five U.S. studies. J Natl Cancer Inst 93: 768-776, 2001.

13. Wolff MS, Toniolo PG, Lee EW, Rivera M and Dubin N: Blood levels of organochlorine residues and risk of breast cancer. J Natl Cancer Inst 85: 648-652, 1993.

14. Hardell L, van Bavel B, Lindström G, Björnfoth H, Orgum P, Carlberg M, Sörensen CS and Graflund M: Adipose tissue concentrations of $\mathrm{p}, \mathrm{p}^{\prime}$-DDE and the risk for endometrial cancer. Gynecol Oncol 95: 706-711, 2004.

15. Pavuk M, Cerhan JR, Lynch CF, Kocan A, Petrik J and Chovancova J: Case-control study of PCBs, other organochlorines and breast cancer in Eastern Slovakia. J Expo Anal Environ Epidemiol 13: 267-275, 2003.

16. Calle EE, Frumkin H, Henley SJ, Savitz DA and Thun MJ: Organochlorines and breast cancer risk. CA Cancer J Clin 52: 301-309, 2002.
17. López-Cervantes M, Torres-Sánchez L, Tobías A and López-Carrillo L: Dichlorodiphenyldichloroethane burden and breast cancer risk: A meta-analysis of the epidemiologic evidence. Environ Health Perspect 112: 207-214, 2004.

18. Ibarluzea Jm J, Fernández MF, Santa-Marina L, Olea-Serrano MF, Rivas AM, Aurrekoetxea JJ, Expósito J, Lorenzo M, Torné P, Villalobos M, et al: Breast cancer risk and the combined effect of environmental estrogens. Cancer Causes Control 15: 591-600, 2004.

19. Cassidy RA, Natarajan S and Vaughan GM: The link between the insecticide heptachlor epoxide, estradiol, and breast cancer. Breast Cancer Res Treat 90: 55-64, 2005.

20. Charlier C, Albert A, Herman P, Hamoir E, Gaspard U, Meurisse $\mathrm{M}$ and Plomteux G: Breast cancer and serum organochlorine residues. Occup Environ Med 60: 348-351, 2003.

21. Engel LS, Hill DA, Hoppin JA, Lubin JH, Lynch CF, Pierce J, Samanic C, Sandler DP, Blair A and Alavanja MC: Pesticide use and breast cancer risk among farmers' wives in the agricultural health study. Am J Epidemiol 161: 121-135, 2005.

22. Cohn BA, Wolff MS, Cirillo PM and Sholtz RI: DDT and breast cancer in young women: New data on the significance of age at exposure. Environ Health Perspect 115: 1406-1414, 2007.

23. Ingber SZ, Buser MC, Pohl HR, Abadin HG, Murray HE and Scinicariello F: DDT/DDE and breast cancer: A meta-analysis. Regul Toxicol Pharmacol 67: 421-433, 2013.

24. Tiemann U: In vivo and in vitro effects of the organochlorine pesticides DDT, TCPM, methoxychlor, and lindane on the female reproductive tract of mammals: A review. Reprod Toxicol 25: 316-326, 2008

25. Gore AC, Walker DM, Zama AM, Armenti AE and Uzumcu M: Early life exposure to endocrine-disrupting chemicals causes lifelong molecular reprogramming of the hypothalamus and premature reproductive aging. Mol Endocrinol 25: 2157-2168, 2011.

26. Wetzel LT, Luempert LG III, Breckenridge CB, Tisdel MO, Stevens JT, Thakur AK, Extrom PJ and Eldridge JC: Chronic effects of atrazine on estrus and mammary tumor formation in female Sprague-Dawley and Fischer 344 rats. J Toxicol Environ Health 43: 169-182, 1994.

27. Young HA, Mills PK, Riordan DG and Cress RD: Triazine herbicides and epithelial ovarian cancer risk in central California. J Occup Environ Med 47: 1148-1156, 2005.

28. Ventura C, Nieto MR, Bourguignon N, Lux-Lantos V, Rodriguez H, Cao G, Randi A, Cocca C and Núñez M: Pesticide chlorpyrifos acts as an endocrine disruptor in adult rats causing changes in mammary gland and hormonal balance. J Steroid Biochem Mol Biol 156: 1-9, 2016.

29. Teitelbaum SL, Gammon MD, Britton JA, Neugut AI, Levin B and Stellman SD: Reported residential pesticide use and breast cancer risk on Long Island, New York. Am J Epidemiol 165: 643-651, 2007.

30. Alavanja MC, Sandler DP, Lynch CF, Knott C, Lubin JH, Tarone R, Thomas K, Dosemeci M, Barker J, Hoppin JA, et al: Cancer incidence in the agricultural health study. Scand J Work Environ Health 31 (Suppl 1): 39-45, discussion 5-7, 2005.

31. Thongprakaisang S, Thiantanawat A, Rangkadilok N, Suriyo T and Satayavivad J: Glyphosate induces human breast cancer cells growth via estrogen receptors. Food Chem Toxicol 59: 129-136, 2013.

32. Pestana D, Teixeira D, Faria A, Domingues V, Monteiro R and Calhau C: Effects of environmental organochlorine pesticides on human breast cancer: Putative involvement on invasive cell ability. Environ Toxicol 30: 168-176, 2015.

33. Lovekamp-Swan T and Davis BJ: Mechanisms of phthalate ester toxicity in the female reproductive system. Environ Health Perspect 111: 139-145, 2003.

34. Chen FP and Chien MH: Lower concentrations of phthalates induce proliferation in human breast cancer cells. Climacteric 17: 377-384, 2014.

35. Hunt PA, Sathyanarayana S, Fowler PA and Trasande L: Female reproductive disorders, diseases, and costs of exposure to endocrine disrupting chemicals in the European Union. J Clin Endocrinol Metab 101: 1562-1570, 2016.

36. Rossing MA, Cushing-Haugen KL, Wicklund KG, Doherty JA and Weiss NS: Risk of epithelial ovarian cancer in relation to benign ovarian conditions and ovarian surgery. Cancer Causes Control 19: 1357-1364, 2008.

37. Johnson NP, Hummelshoj L, Abrao MS, Adamson GD, Allaire C, Amelung V, Andersson E, Becker C, Birna Ardal KB, Bush D, et al; World Endometriosis Society Montpellier Consortium: Consensus on current management of endometriosis. Hum Reprod 28: 1552-1568, 2013. 
38. Roy D, Morgan M, Yoo C, Deoraj A, Roy S, Yadav VK, Garoub M, Assaggaf $\mathrm{H}$ and Doke M: Integrated bioinformatics, environmental epidemiologic and genomic approaches to identify environmental and molecular links between endometriosis and breast cancer. Int J Mol Sci 16: 25285-25322, 2015.

39. European Food Safety Authority: Scientific opinion on the risks to public health related to the presence of bisphenol A (BPA) in foodstuffs. EFSA J 13: 3978, 2015.

40. Caserta D, Ciardo F, Bordi G, Guerranti C, Fanello E, Perra G, Borghini F, La Rocca C, Tait S, Bergamasco B, et al: Correlation of endocrine disrupting chemicals serum levels and white blood cells gene expression of nuclear receptors in a population of infertile women. Int J Endocrinol 2013: 510703, 2013.

41. Hengstler JG, Foth H, Gebel T, Kramer P-J, Lilienblum W, Schweinfurth H, Völkel W, Wollin KM and Gundert-Remy U: Critical evaluation of key evidence on the human health hazards of exposure to bisphenol A. Crit Rev Toxicol 41: 263-291, 2011.

42. Soto AM, Brisken C, Schaeberle C and Sonnenschein C: Does cancer start in the womb? altered mammary gland development and predisposition to breast cancer due to in utero exposure to endocrine disruptors. J Mammary Gland Biol Neoplasia 18 : 199-208, 2013

43. Durando M, Kass L, Piva J, Sonnenschein C, Soto AM, Luque EH and Muñoz-de-Toro M: Prenatal bisphenol A exposure induces preneoplastic lesions in the mammary gland in Wistar rats. Environ Health Perspect 115: 80-86, 2007.

44. Murray TJ, Maffini MV, Ucci AA, Sonnenschein C and Soto AM Induction of mammary gland ductal hyperplasias and carcinoma in situ following fetal bisphenol A exposure. Reprod Toxicol 23: 383-390, 2007.

45. van der Ven LT, van de Kuil T, Leonards PE, Slob W, Lilienthal H, Litens S, Herlin M, Håkansson H, Cantón RF, van den Berg M, et al: Endocrine effects of hexabromocyclododecane (HBCD) in a one-generation reproduction study in Wistar rats. Toxicol Lett 185: 51-62, 2009.

46. Jenkins S, Raghuraman N, Eltoum I, Carpenter M, Russo J and Lamartiniere CA: Oral exposure to bisphenol a increases dimethylbenzanthracene-induced mammary cancer in rats. Environ Health Perspect 117: 910-915, 2009.

47. Acevedo N, Davis B, Schaeberle CM, Sonnenschein C and Soto AM: Perinatally administered bisphenol a as a potential mammary gland carcinogen in rats. Environ Health Perspect 121 1040-1046, 2013.

48. Dairkee SH, Seok J, Champion S, Sayeed A, Mindrinos M, Xiao W, Davis RW and Goodson WH: Bisphenol A induces a profile of tumor aggressiveness in high-risk cells from breast cancer patients. Cancer Res 68: 2076-2080, 2008.

49. Montes-Grajales D, Bernardes GJ and Olivero-Verbel J: Urban endocrine disruptors targeting breast cancer proteins. Chem Res Toxicol 29: 150-161, 2016.

50. Swan SH: Intrauterine exposure to diethylstilbestrol: Long-term effects in humans. APMIS 108: 793-804, 2000.

51. International Agency for Research on Cancer (IARC): Monographs on the Evaluation of the Carcinogenic Risk of Chemicals to Humans. Vol 72. Hormonal Contraception and Post-Menopausal Hormonal Therapy, Lyon, pp291-294, 1999.

52. Cook JD, Davis BJ, Goewey JA, Berry TD and Walker CL: Identification of a sensitive period for developmental programming that increases risk for uterine leiomyoma in Eker rats. Reprod Sci 14: 121-136, 2007.

53. World Health Organization (WHO), International Agency for Research on Cancer (IARC): Monographs on the Evaluation of the Carcinogenic Risk of Chemicals to Humans. Beryllium, cadmium, mercury, and exposures in the glass manufacturing industry. Vol. 58, IARC, Lyon, 1993.

54. Liu Z, Yu X and Shaikh ZA: Rapid activation of ERK1/2 and AKT in human breast cancer cells by cadmium. Toxicol Appl Pharmacol 228: 286-294, 2008.

55. McElroy JA, Shafer MM, Trentham-Dietz A, Hampton JM and Newcomb PA: Cadmium exposure and breast cancer risk. J Natl Cancer Inst 98: 869-873, 2006.

56. Akesson A, Julin B and Wolk A: Long-term dietary cadmium intake and postmenopausal endometrial cancer incidence: A population-based prospective cohort study. Cancer Res 68 6435-6441, 2008.

57. Julin B, Wolk A, Bergkvist L, Bottai M and Åkesson A: Dietary cadmium exposure and risk of postmenopausal breast cancer: A population-based prospective cohort study. Cancer Res 72: 1459-1466, 2012
58. Mohapatra P, Preet R, Das D, Satapathy SR, Siddharth S, Choudhuri T, Wyatt MD and Kundu CN: The contribution of heavy metals in cigarette smoke condensate to malignant transformation of breast epithelial cells and in vivo initiation of neoplasia through induction of a PI3K-AKT-NFKB cascade. Toxicol Appl Pharmacol 274: 168-179, 2014.

59. Rahim F, Jalali A and Tangestani R: Breast cancer frequency and exposure to cadmium: A meta-analysis and systematic review. Asian Pac J Cancer Prev 14: 4283-4287, 2013.

60. Moysich KB, Shields PG, Freudenheim JL, Schisterman EF, Vena JE, Kostyniak P, Greizerstein H, Marshall JR, Graham S and Ambrosone CB: Polychlorinated biphenyls, cytochrome P4501A1 polymorphism, and postmenopausal breast cancer risk. Cancer Epidemiol Biomarkers Prev 8: 41-44, 1999.

61. Sergentanis TN and Economopoulos KP: Four polymorphisms in cy tochrome P450 1A1 (CYP1A1) gene and breast cancer risk: A meta-analysis. Breast Cancer Res Treat 122: 459-469, 2010.

62. Cohn BA, Terry MB, Plumb M and Cirillo PM: Exposure to polychlorinated biphenyl (PCB) congeners measured shortly after giving birth and subsequent risk of maternal breast cancer before age 50. Breast Cancer Res Treat 136: 267-275, 2012.

63. Bouker KB and Hilakivi-Clarke L: Genistein: Does it prevent or promote breast cancer? Environ Health Perspect 108: 701-708, 2000.

64. Shu XO, Jin F, Dai Q, Wen W, Potter JD, Kushi LH, Ruan Z, Gao YT and Zheng W: Soyfood intake during adolescence and subsequent risk of breast cancer among Chinese women. Cancer Epidemiol Biomarkers Prev 10: 483-488, 2001.

65. Trock B, White BL, Clarke R and Hilakivi-Clarke L: Meta-analysis of soy intake and breast cancer risk. Third International Symposium on the Role of Soy in Preventing and Treating Chronic Disease. J Nutr 130: 653S-680S, 2000.

66. Messina MJ and Loprinzi CL: Soy for breast cancer survivors: A critical review of the literature. J Nutr 131 (Suppl 11): 3095S-3108S, 2001.

67. This P, De La Rochefordière A, Clough K, Fourquet A and Magdelenat H; Breast Cancer Group of the Institut Curie: Phytoestrogens after breast cancer. Endocr Relat Cancer 8: 129-134, 2001.

68. Horn-Ross PL, John EM, Canchola AJ, Stewart SL and Lee MM: Phytoestrogen intake and endometrial cancer risk. J Natl Cancer Inst 95: 1158-1164, 2003.

69. Unfer V, Casini ML, Costabile L, Mignosa M, Gerli S and Di Renzo GC: Endometrial effects of long-term treatment with phytoestrogens: A randomized, double-blind, placebo-controlled study. Fertil Steril 82: 145-148, quiz 265, 2004.

70. Gaete L, Tchernitchin AN, Bustamante R, Villena J, Lemus I, Gidekel M, Cabrera G and Astorga P: Daidzein-estrogen interaction in the rat uterus and its effect on human breast cancer cell growth. J Med Food 15: 1081-1090, 2012.

71. Greathouse KL, Bredfeldt T, Everitt JI,Lin K, Berry T, Kannan K, Mittelstadt ML, Ho SM and Walker CL: Environmental estrogens differentially engage the histone methyltransferase EZH2 to increase risk of uterine tumorigenesis. Mol Cancer Res 10: 546-557, 2012.

72. Kang NH, Hwang KA, Lee HR, Choi DW and Choi KC: Resveratrol regulates the cell viability promoted by $17 \beta$-estradiol or bisphenol A via down-regulation of the cross-talk between estrogen receptor $\alpha$ and insulin growth factor-1 receptor in BG-1 ovarian cancer cells. Food Chem Toxicol 59: 373-379, 2013.

73. Reaves DK, Ginsburg E, Bang JJ and Fleming JM: Persistent organic pollutants and obesity: Are they potential mechanisms for breast cancer promotion? Endocr Relat Cancer 22: R69-R86, 2015.

74. Patterson AR, Mo X, Shapiro A, Wernke KE, Archer TK and Burd CJ: Sustained reprogramming of the estrogen response after chronic exposure to endocrine disruptors. Mol Endocrinol 29: 384-395, 2015.

75. Burgio E and Migliore L: Towards a systemic paradigm in carcinogenesis: Linking epigenetics and genetics. Mol Biol Rep 42: 777-790, 2015

76. Berretta M, Di Francia R and Tirelli U: The new oncologic challenges in the 3RD millennium. WCRJ 1: e133, 2014.

77. Del Buono A, D'Orta A, Del Buono R, Del Buono MG, De Monaco A and Marullo MN: Relationship between diet and heavy metals in high risk of the environmental toxicity areas. Implication for cancer prevention. WCRJ 1: e411, 2014. 